\title{
TMF criteria for Lost Foam Casting aluminum alloys
}

\author{
S. TABIBIAN ${ }^{1,2,3}$, E. CHARKALUK ${ }^{2}$, A. CONSTANTINESCU ${ }^{3}$, F. SZMYTKA $^{1}$ and A. OUDIN ${ }^{1}$ \\ ${ }_{1}^{1}$ Automotive Research and Innovation Division, PSA Peugeot Citroën Route de Gisy, Vélizy-Villacoublay 78943, France \\ ${ }^{2}$ LML CNRS UMR 8107, Laboratoire Mécanique de Lille, Ecole Centrale de Lille, Cité Scientifique 59650 Villeneuve d'Ascq, France \\ ${ }^{3}$ LMS CNRS UMR 7649, Laboratoire Mécanique Solides, Ecole Polytechnique, Route Saclay, 91120 - Palaiseau, France
}

ABSTRACT The purpose of this paper is to define a thermo-mechanical fatigue criterion in order to predict the failure of aluminum alloys components issued with the lost foam casting process and used in particular in the automotive industry. The microstructure of the studied materials (A356-A319 aluminum alloys) is clearly affected by the lost foam casting process which can directly affect the mechanical properties, the damage mechanisms and the fatigue failure of specimens and components. The major problem in defining a predictive fatigue criterion in this case is the fact that it should be applicable for the component which is submitted to complex multiaxial thermo-mechanical loadings. Since many years, energy-based criteria have been used to predict fatigue failure of this class of materials. Then, different energy-based criteria are tested in order to take into account different types of triaxiality and mean stress effects corrections. The fatigue lifetime results predicted by both of them show a good agreement with experimental results.

Keywords aluminum alloys; energy-based criterion; lost foam casting; low cycle fatigue.

NOMENCLATURE

$$
\begin{aligned}
\operatorname{tr}(\sigma) & =\text { trace of the stress tensor } \\
A, B & =\text { parameters of the fatigue power law } \\
E & =\text { Young's modulus } \\
N_{f} & =\text { fatigue lifetime } \\
R^{2} & =\text { correlation coefficient } \\
R_{\epsilon} & =\text { strain ratio } \\
T_{\min } \text { and } T_{\max } & =\text { minimum and maximum temperature on a cycle } \\
W & =\text { plastic dissipated energy per cycle } \\
W_{E \sigma \Delta \epsilon} & =\text { STW criterion } \\
W_{\sigma_{\text {eff }}} & =\text { Heitmann criterion } \\
W_{\sigma_{H}} & =\text { Amiable criterion } \\
W_{\sigma_{\max }} & =\text { Koh criterion } \\
W_{\Delta \sigma} & =\text { Haddar criterion } \\
\Delta \epsilon & =\text { strain amplitude } \\
\Delta \sigma & =\text { stress amplitude } \\
\dot{\epsilon} & =\text { strain rate } \\
\dot{\epsilon}_{p} & =\text { plastic strain rate } \\
\sigma & =\text { stress tensor } \\
\sigma_{\max } & =\text { maximum stress on a fatigue cycle } \\
\sigma_{\text {eff }} & =\text { effective stress } \\
\sigma_{H}^{\max } & =\text { maximum hydrostatic pressure } \\
\phi & =\text { fatigue parameter }
\end{aligned}
$$




\section{INTRODUCTION}

The prediction of fatigue and failure of structures subjected to thermo-mechanical loadings is nowadays an important challenge and has been the subject of major efforts in the last few decades. ${ }^{1-3}$ Generally, the main objective is not just safety of design, but also lifetime prediction without intermediate monitoring. Therefore engineers need robust computational methods for the prediction of macroscopic fatigue crack initiation which must guarantee the integrity of the structures during the complete lifetime. One can cite many research works on crack initiation prediction in different industrial area: aeronautic industry, ${ }^{4,5}$ automobile industry ${ }^{6-10}$ or nuclear industry. ${ }^{11-13}$ These different works are mainly based on two key features: (i) the modelling of the visco-plastic mechanical properties and (ii) the modelling of the damage mechanisms. In this context, TMF lifetime assessment approaches based on a simple constitutive visco-plastic law and on the dissipated plastic energy as a fatigue crack initiation criteria were proposed in the last years, in particular for the design of aluminum alloys in automotive components. 9

Aluminum alloys are extensively used due to their high strength to weight ratio, good machinability, corrosion resistance, optimum surface finish and high electrical and thermal conductivity. ${ }^{14}$ More particularly, $\mathrm{Al}-\mathrm{Si}-\mathrm{Mg}-\mathrm{Cu}$ alloys obtained by a die casting process are commonly used in the automotive industry, mainly for different engine parts (cylinder head, crankcase, ... ) which experience severe high temperature loading cycles, capable of producing thermo-mechanical low-cycle fatigue, which can lead to component failure in service. ${ }^{6,10}$

Recently due to process cost reduction goals, conventional Die Casting (DC) process is being replaced by Lost Foam Casting (LFC) process. ${ }^{15,16}$ LFC uses almost a quarter less energy and a third less molten metal than conventional casting. ${ }^{17}$ The advantages of LFC over DC process are then: the low cost of foam, unbounded sand, possibility of complex shapes with internal channels, elimination of cores and parting lines and reduced grinding and finishing costs. ${ }^{18}$

The main disadvantage of LFC is the presence of defects which is caused by entrapment of gases in the solidifying metal. This is due to inadequate permeability, and high moisture levels in bonded green sand. ${ }^{19}$ This can be due also to a possible entrapment of liquid styrene during solidification. Moreover, LFC process cooling rate is relatively slow compared with DC process (LFC around $0.8^{\circ} \mathrm{C} \mathrm{s}^{-1}$ and DC around $\left.30^{\circ} \mathrm{C} \mathrm{s}^{-1}\right){ }^{18}$ This leads to a coarser microstructure when measured in term of DAS (Dendrite Arm Spacing). Beside, the porosity and inclusions are increased and clustered. Iron, magnesium and copper containing intermetallics are found in the microstructure of these alloys. Iron-containing intermetallics phases are then the most common among the three and are sometimes deleterious to mechanical properties. ${ }^{18,20,21}$ All of these aspects can significantly reduce overall mechanical properties and the fatigue life of the component.

In this study, LCF (Low Cycle Fatigue) and TMF (Thermo-Mechanical Fatigue) tests were performed in order to explore the influences of over-aging, chemical composition (A319, A356) and casting process (LFC, DC) on mechanical properties and fatigue lifetime. In a first part, the fatigue tests are presented and the cyclic behaviour of the considered materials is discussed. In a second part, several energy based fatigue criteria are proposed and their interest and relevance are discussed in the case of the A319 alloy. The influence of the casting process (LFC and DC) is analysed by comparing the experimental and the computed fatigue lifetimes in the case of LCF isothermal tests.

\section{EXPERIMENTS}

\section{Materials and composition}

The studied materials are two aluminum-silicon alloys used in the automotive industry: A356 with T7 heat treatment and A319 without heat treatment. Chemical composition of both alloys are illustrated in Table 1 . This study focuses essentially on the materials obtained by LFC process. However, processes have a great influence on the microstructure of the materials as it was already illustrated in Ref. [22]. Therefore, some comparisons between both casting processes are made. The over-aging has been determined by the stabilisation both in terms of mechanical properties and of microstructure of the material. In this case the over-aged condition corresponds to the heating of material at $250^{\circ} \mathrm{C}$ for $200 \mathrm{~h}$. A356 and A319 were studied in nonaged and over-aged conditions. Some SEM (Scanning Electron Microscopy) observations have been done and two pre-eutectic iron-containing intermetallics were observed in the microstructure: $\alpha-\mathrm{AlFeSi}$ and $\beta-\mathrm{AlFeSi},{ }^{22}$ which is consistent with previous observations. ${ }^{23}$

\section{Experimental procedures}

In order to study the cyclic mechanical properties, the fatigue lifetime and the damage mechanisms of LFC materials, strain controlled Low Cycle Fatigue (LCF) and Thermo Mechanical Fatigue (TMF ${ }^{2,3}$ tests have been performed. All samples were extracted from the intervalve zones which are considered as critical zones for TMF in the fire deck. The dimensions of the specimen are given of Fig. 2. 
Table 1 Chemical composition of LFC A356 and A319

\begin{tabular}{lcccccccccrrr}
\hline Material & $\mathrm{Si} \%$ & $\mathrm{Mn} \%$ & $\mathrm{Fe} \%$ & $\mathrm{Mg} \%$ & $\mathrm{Cu} \%$ & $\mathrm{Zn} \%$ & $\mathrm{Ti} \%$ & $\mathrm{Ni} \%$ & $\mathrm{Srppm}$ & $\mathrm{Pppm}$ & $\mathrm{V} \%$ & $\mathrm{Zr} \%$ \\
\hline A356 (T7) & 6.61 & 0.01 & 0.11 & 0.30 & 0.09 & 0.006 & 0.10 & 0.004 & 0.001 & 0.002 & 0.008 & 0.001 \\
A319 & 7.18 & 0.15 & 0.43 & 0.32 & 3.17 & 0.19 & 0.05 & 0.010 & 0.020 & 0.010 & 0.006 & 0.002 \\
\hline
\end{tabular}

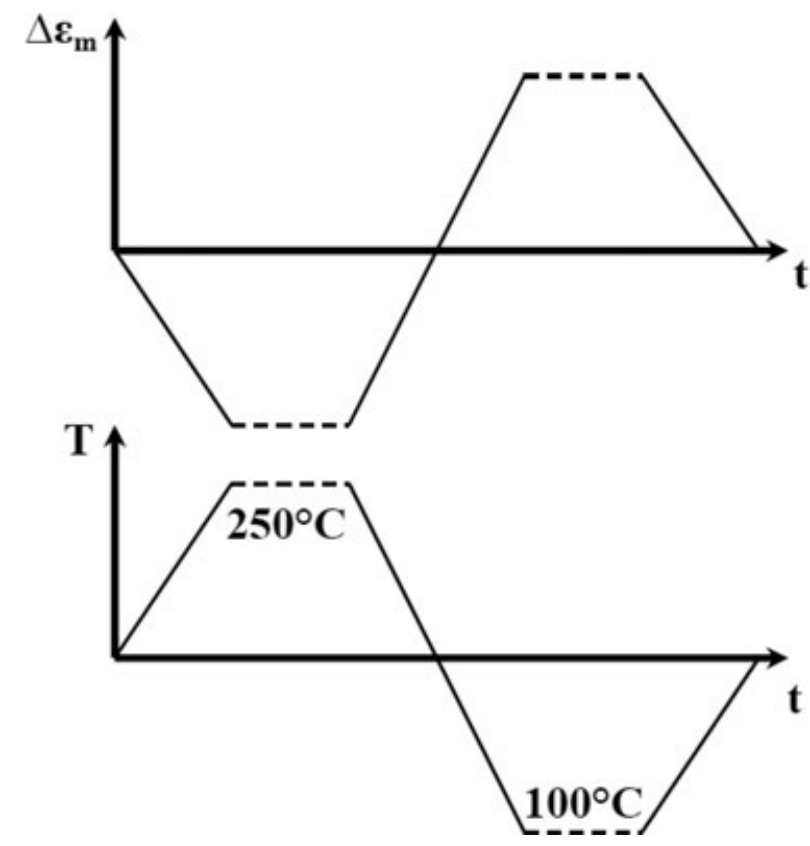

Fig. 1 Cyclic strain and temperature loadings with or without dwell time.

TMF tests include some classical out of phase tests, with dwell time at maximum or minimum temperatures, as shown on Fig. 1. Maximum and minimum temperatures are defined as $250^{\circ} \mathrm{C}$ and $100^{\circ} \mathrm{C}$, respectively in order to be close to real in-service temperature ranges. These tests were conducted under variable mechanical strain ranges $\Delta \epsilon=0.2-0.6 \%$ ), with a mechanical strain ratio $R_{\epsilon}=-1$. In the case of TMF tests with dwell time, the strain and

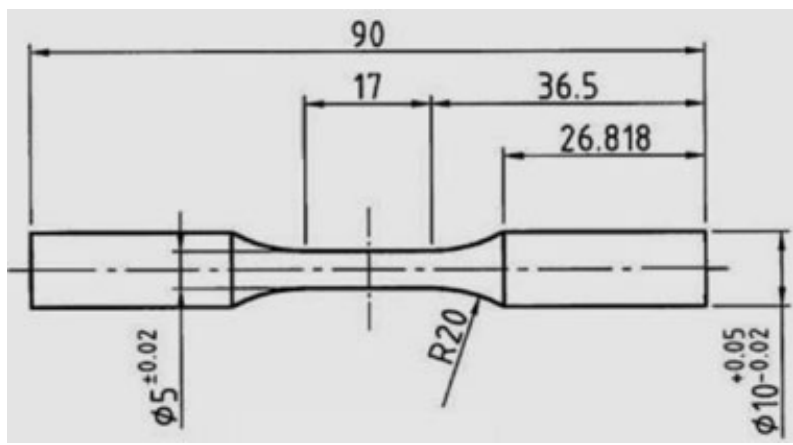

Fig. 2 Dimension of the LCF tests specimens, in millimetre.

the temperature are maintained during $50 \mathrm{~s}$. LCF and TMF tests were conducted with a mechanical stain rate of $\dot{\epsilon}=10^{-3} s^{-1}$ (Table 2).

\section{Results and discussion}

Figures 3 and 4 describe the cyclic mechanical behaviour of the A356 and A319 alloys for aged and non-aged conditions and for both processes, LFC and DC. They correspond to isothermal LCF tests at $250^{\circ} \mathrm{C}$ and TMF tests without dwell time. As strain controlled tests are realized in each case, on the left-hand side, the cyclic evolution of the maximum induced axial stress is presented and, on the right-hand side, the corresponding stabilised measured hysteresis loop representing the variation of the axial stress versus the imposed axial strain. The stabilized hysteresis loop is defined as a standard strain-stress curve, obtained between the high and low softening domains in

Table 2 Tests condition summary

\begin{tabular}{llllll}
\hline Test & Dwell time & $\mathrm{T}\left({ }^{\circ} \mathrm{C}\right)$ & Casting process & $\Delta \epsilon(\%)-\mathrm{A} 356$ & $\Delta \epsilon(\%)-\mathrm{A} 319$ \\
\hline LCF & 0 & 250 & LFC & $0.4-0.6$ & $0.1-0.6$ \\
LCF & 0 & 250 & DC & $1-2$ & $0.5-0.8$ \\
LCF & 0 & 200 & LFC & $0.2-1.4$ & $0.1-0.5$ \\
LCF & 0 & 200 & DC & $1-3$ & $0.4-0.7$ \\
LCF & 0 & 150 & LFC & $0.4-0.8$ & $0.1-0.3$ \\
LCF & 0 & 150 & DC & $0.8-2.5$ & $0.4-0.6$ \\
TMF & 0 & $100-250$ & LFC & $0.3-0.8$ & $0.3-0.6$ \\
TMF & $50 \mathrm{~s}$ at $T_{\max }$ & $100-250$ & LFC & 0.5 & 0.4 \\
TMF & $50 \mathrm{~s}$ at $T_{\max }$ and $T_{\min }$ & $100-250$ & LFC & 0.5 & 0.4 \\
\hline
\end{tabular}

Notes: LCF denotes Low Cycle Fatigue and TMF denotes Thermo-Mechanical Fatigue. 
a

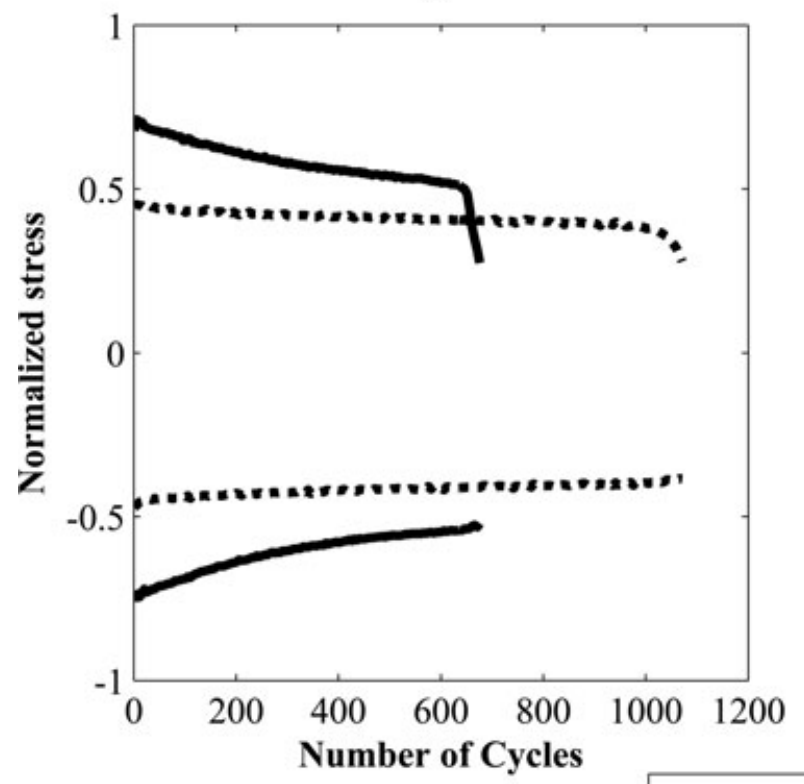

C

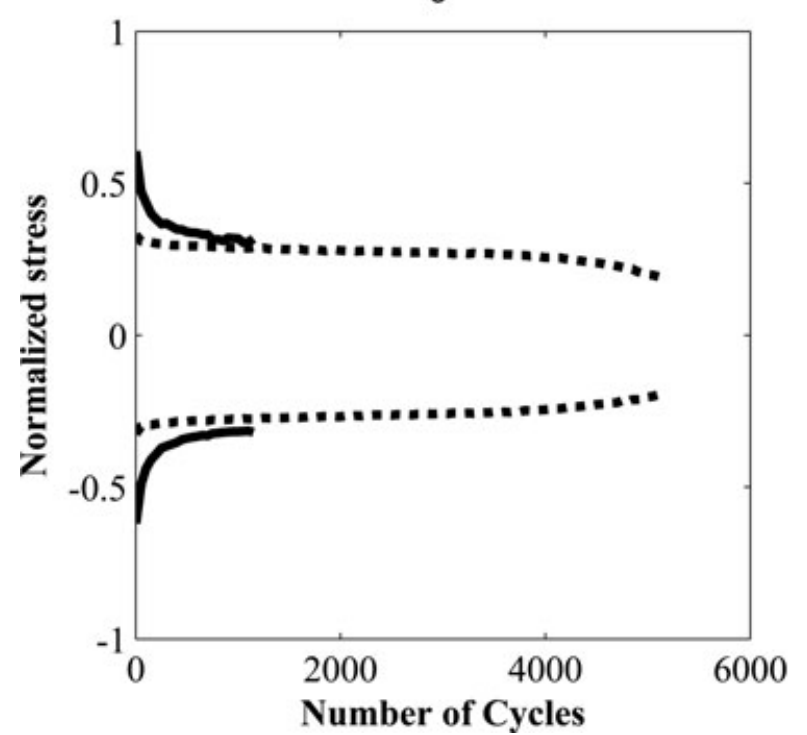

b

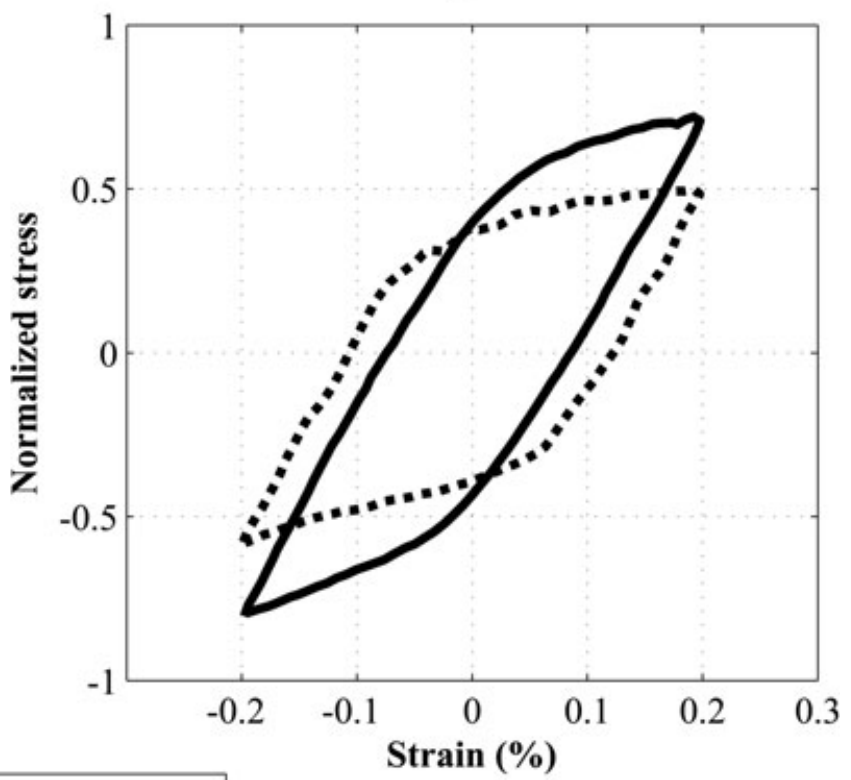

Non aged

Overaged

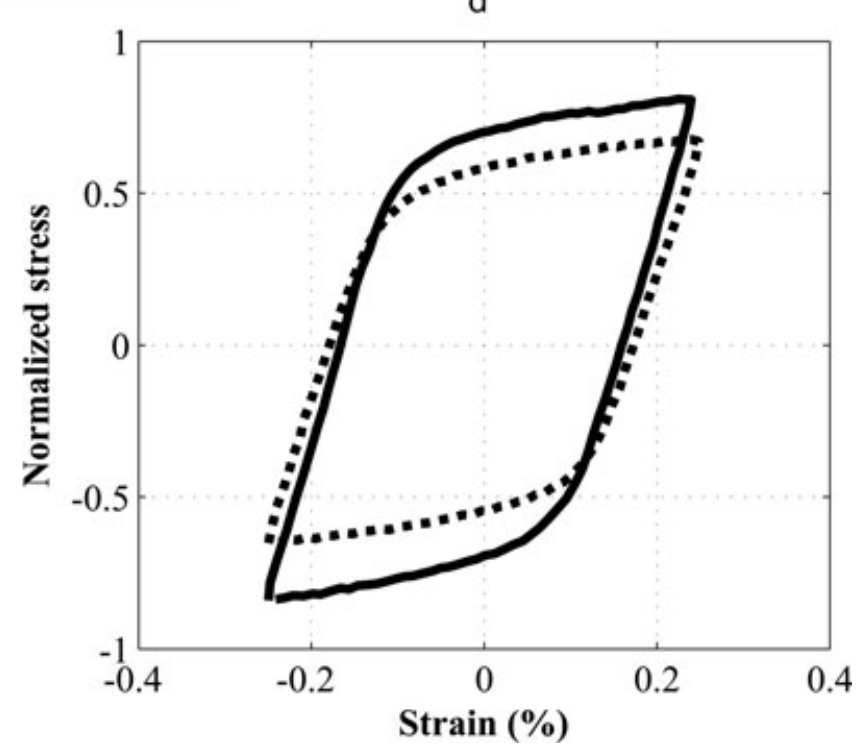

Fig. 3 LCF tests at $250^{\circ} \mathrm{C}$ (a) Axial stress cyclic evolution versus number of cycles: aged and non-aged LFC-A319; (b) Stabilized hysteresis loop: aged and non-aged LFC-A319; (c) Axial stress cyclic evolution versus number of cycles: aged and non-aged LFC-A356; (d) Stabilized hysteresis loop: aged and non-aged LFC-A356.

the cyclic material behaviour, where the maximal stress over the cycle is almost constant. In both cases, the axial stresses are normalized by the maximum stress value obtained in the first cycle. However, in the next paragraphs, the 'normalized maximum stress' will be simply denoted by the 'maximum stress'. On these figures, fatigue lifetime is defined by a $10 \%$ drop of maximum stress, before the fracture of specimen.

\section{Influence of aging conditions}

Figures 3 and 4 illustrate the influences of aging on LFC alloys for both LCF-TMF tests. Figures on the left-hand side represent the evolution of the maximum induced stress versus the number of applied cycles. The results show that the non-aged A356 has a sudden reduction of maximum stress in the few first hundred cycles and then 
a
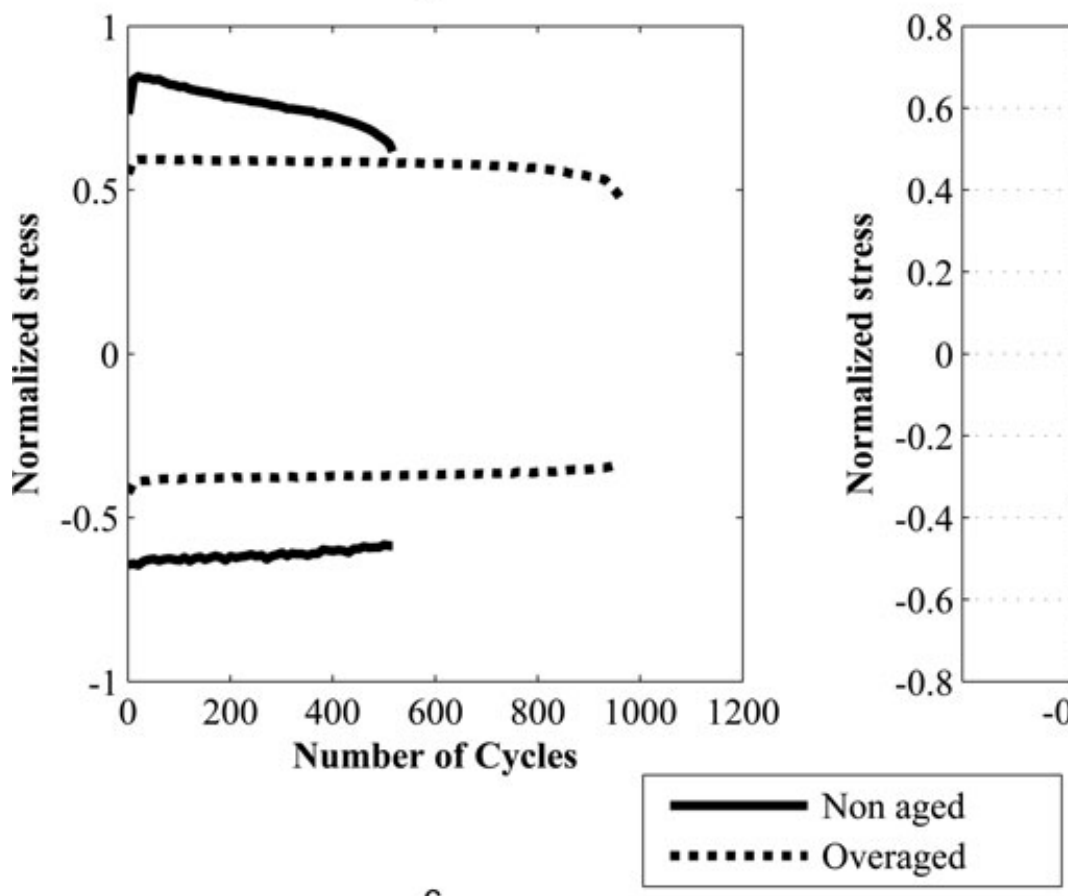

C

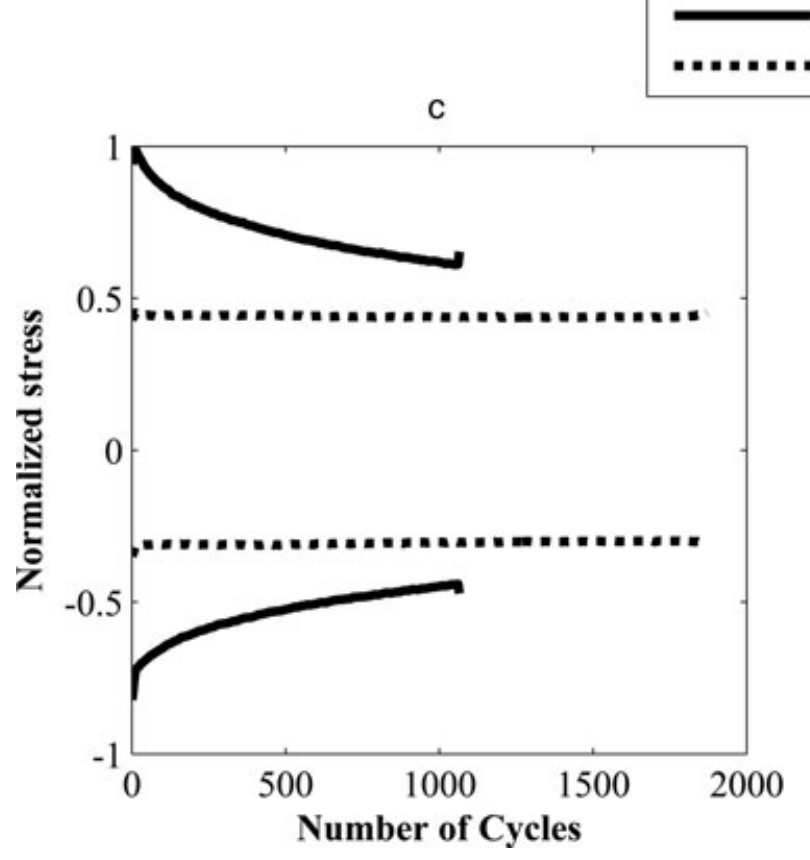

b

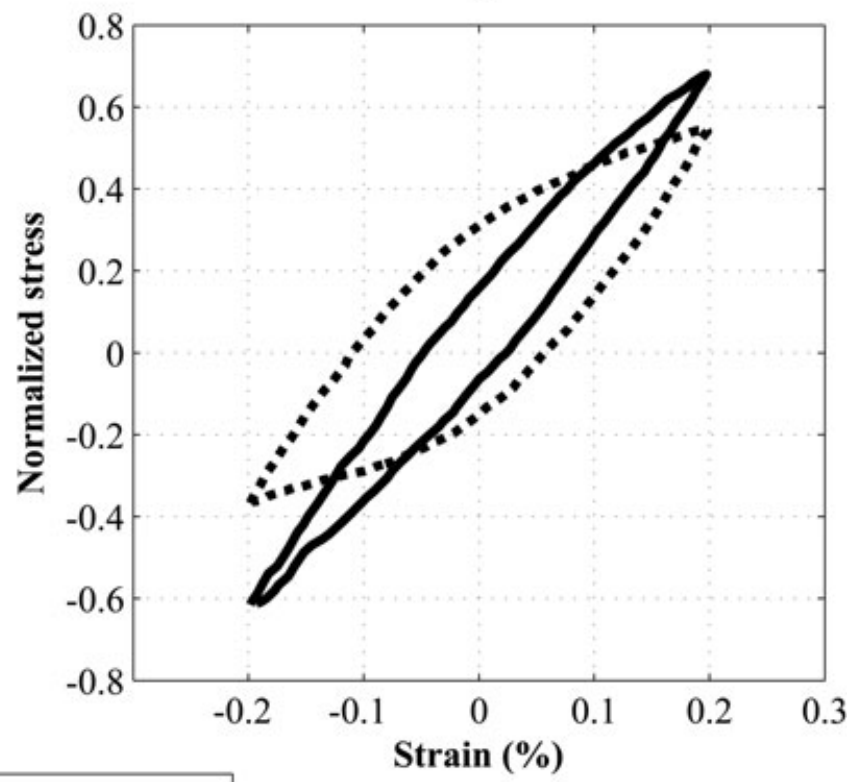

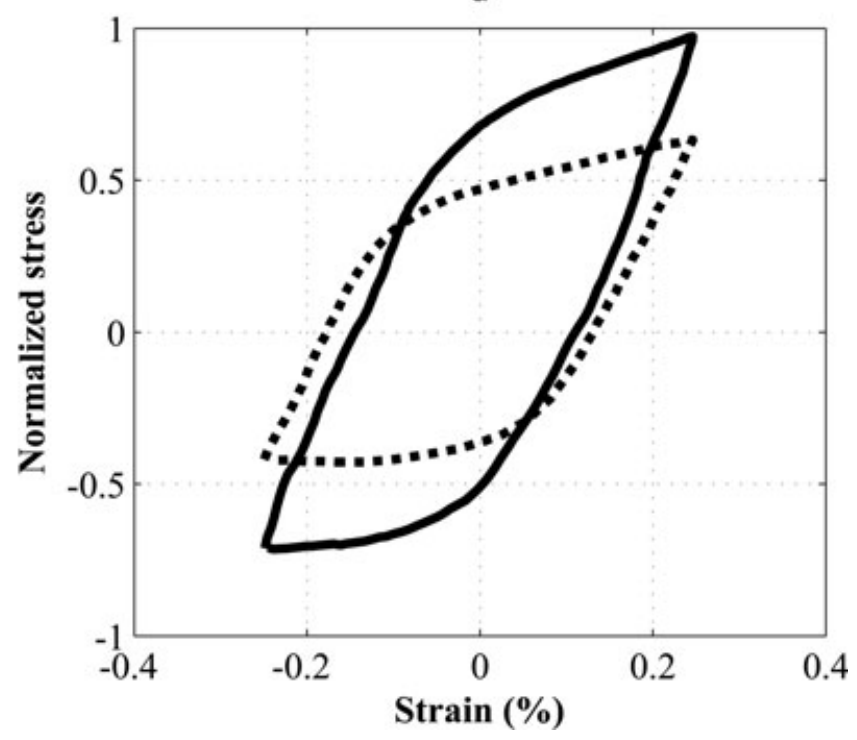

Fig. 4 TMF tests between $100^{\circ} \mathrm{C}$ and $250^{\circ} \mathrm{C}$ (a) Axial stress cyclic evolution versus number of cycles: aged and non-aged LFC-A319; (b) Stabilized hysteresis loop: aged and non-aged LFC-A319; (c) Axial stress cyclic evolution versus number of cycles: aged and non-aged LFC-A356 ; (d) Stabilized hysteresis loop: aged and non-aged LFC-A356.

reach the stabilized state, although the aged A356 softens immediately to the stabilized state.

On the contrary, non-aged A319 tends to harden in the few first cycles, especially in TMF cases. Then it softens slowly and achieves the stabilized state after approximately 400 cycles. The difference of aging evolution between $\mathrm{A} 356$ and $\mathrm{A} 319$ can certainly be explained by the presence of $\theta-\mathrm{Al}_{2} \mathrm{Cu}$ phases which retain the hardening effects at high temperatures. ${ }^{24}$ In the case of TMF tests, one can also note on Fig. 4 that a positive mean stress is initially observed. This is due to the temperature variations during a cycle and the evolution of the corresponding yield locus. Then, in this case, the observed softening is certainly due to a combination of aging and mean stress relaxation. Both LFC materials (A319 and A356) were subjected to higher stresses in the non-aged condition. The subsequent evolution of the microstructure takes place during age hardening. This evolution 
Table 3 Fatigue lifetimes of aged LFC A319 alloy, according to TMF tests with or without dwell time

\begin{tabular}{llr}
\hline Specimen & Dwell time & $\begin{array}{c}\text { Nf (number of } \\
\text { cycles to failure) }\end{array}$ \\
\hline 1 & 0 & 71 \\
2 & 0 & 195 \\
3 & 0 & 2034 \\
4 & 0 & 226 \\
5 & 0 & 4134 \\
6 & 0 & 220 \\
7 & 0 & 943 \\
8 & 0 & 328 \\
9 & 0 & 445 \\
10 & 0 & 349 \\
11 & $50 \mathrm{~s}$ at $T_{\max }$ & 429 \\
12 & $50 \mathrm{~s}$ at $T_{\max }$ & 325 \\
13 & $50 \mathrm{~s}$ at $T_{\max }$ and $T_{\min }$ & 142 \\
14 & $50 \mathrm{~s}$ at $T_{\max }$ and $T_{\min }$ & 303 \\
\hline
\end{tabular}

takes place for temperatures higher that $200^{\circ} \mathrm{C}$. The successive transformations of precipitations produce larger precipitates, so that the matrix hardening decreases. ${ }^{25}$

Figures 3 and 4 on the right-hand side represent the hysteresis strain-stress loops of stabilized cycles, as defined previously. In all of fatigue tests (LCF or TMF), it is revealed that for the same strain range, the yield strength is superior in non-aged conditions, which induces lower plastic strain ranges.

\section{Influence of compositions}

Isothermal cyclic behaviour of both LFC materials at $250^{\circ} \mathrm{C}$ are compared in Fig. 3 in order to study the effects of chemical composition on fatigue lifetime and mechanical properties. Hysteresis strain-stress loops of LFC A319 shows systematically superior yield strength compared with LFC A356, whatever the aged condition (overaged/non-aged) of the material. Then, for the same strain range, the induced plastic strain is greater for LFC A356 in comparison with LFC A319.

Whatever the aging condition (over-aged/non-aged), the maximum stress level is higher in TMF tests than LCF tests (see Fig. 4). TMF lifetime of different specimens are compared in Table 3 and 4 . These tests are conducted with or without dwell time at maximum and minimum temperatures. The fatigue lifetime of LFC materials is significantly reduced by dwell time at maximum and minimum temperatures. The results are drastically scattered although cyclic mechanical behaviour are almost similar.

\section{Influence of casting process}

In this section, hysteresis strain-stress loops were compared for stabilized cycles of LFC-A319 and DC-A319,
Table 4 Fatigue lifetimes of aged LFC A356 alloy, according to TMF tests with or without dwell time

\begin{tabular}{llr}
\hline Specimen & Dwell time & $\begin{array}{c}\text { Nf (number of } \\
\text { cycles to failure) }\end{array}$ \\
\hline 1 & 0 & 1878 \\
2 & 0 & 697 \\
3 & 0 & 3491 \\
4 & 0 & 1904 \\
5 & 0 & 4661 \\
6 & 0 & 796 \\
7 & 0 & 178 \\
8 & 0 & 1971 \\
9 & 0 & 507 \\
10 & 0 & 131 \\
11 & 0 & 442 \\
12 & 0 & 1414 \\
13 & $50 \mathrm{~s}$ at $T_{\max }$ & 758 \\
14 & $50 \mathrm{~s}$ at $T_{\max }$ & 316 \\
15 & $50 \mathrm{~s}$ at $T_{\max }$ and $T_{\min }$ & 1091 \\
16 & $50 \mathrm{~s}$ at $T_{\max }$ and $T_{\min }$ & 100 \\
\hline
\end{tabular}

in over-aged condition. Figure 5 illustrates the effects of casting process on fatigue lifetime and cyclic mechanical behaviour of A319. The results show that the cyclic mechanical properties stay quite identical for both casting processes. It can be underlined that the same type of comparisons were made for A356 and the stabilized strain-stress loops in the same test condition (strain range, temperature, aging condition) are similar also for both casting processes.

Therefore it seems that casting process does not affect the cyclic mechanical behaviour of the considered materials. On the contrary, the obtained lifetimes corresponding to the Fig. 5a clearly demonstrate that even if the strain-stress hysteresis loop corresponding to a stabilized state are quite not affected by the process, a drastic decrease of the lifetime of LFC materials is systematically observed.

\section{FATIGUE LIFETIME ASSESSMENT}

The experimental results previously presented will be now analysed using a series of fatigue criteria essentially based on the dissipated energy per cycle. We assume here a standard power law

$\phi=A\left(N_{f}\right)^{B}$,

where $\phi$ denotes the fatigue parameter, $N_{f}$ the lifetime (number of cycles to failure), and $A$ and $B$ are two real values material parameters. The fatigue parameter $\phi$ has been computed from the stabilized cycles (see Figs 3 and 4), which corresponds to an elasto-plastic shakedown cycle in a structural computation. As previously stated, the 
a

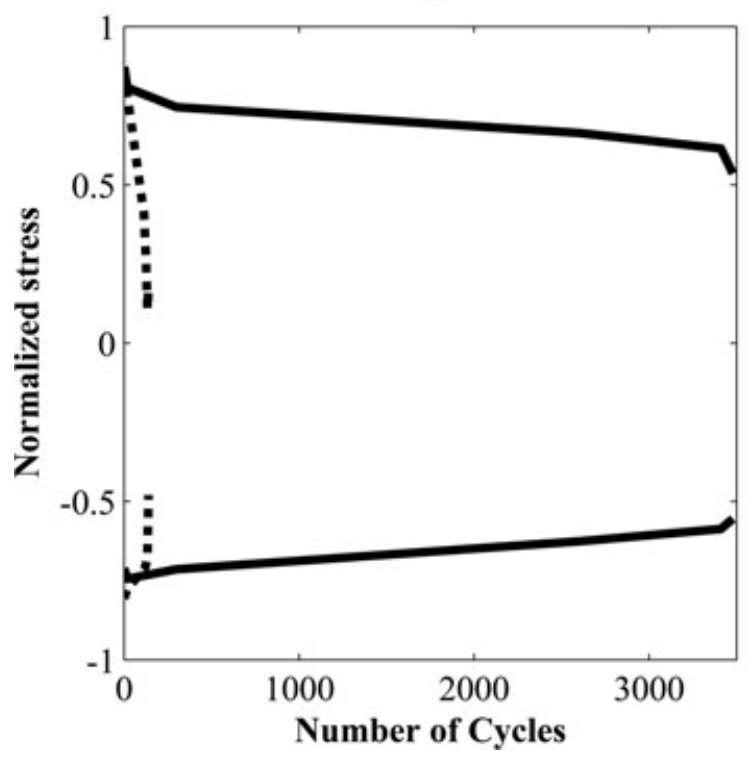

b

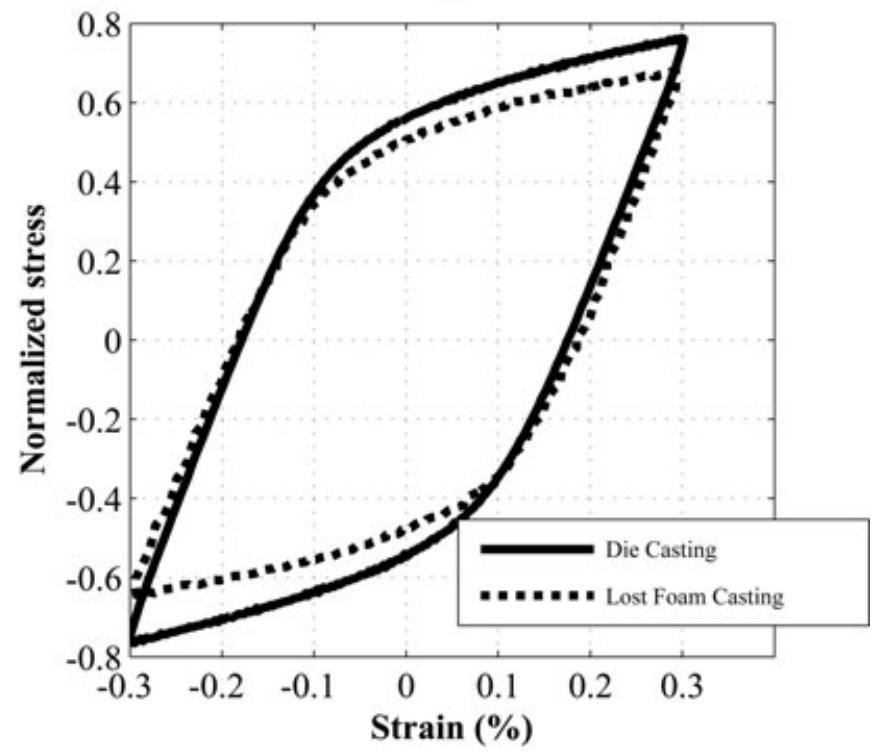

Fig. 5 A319-LFC and A319-DC comparisons (a) Axial stress cyclic evolution versus number of cycles; (b) Stabilized hysteresis loop.

number of cycles to failure, $N_{f}$ has been defined by a $10 \%$ stress drop with respect to the stabilized cycles.

The different criteria are:

(i) Smith-Topper-Watson denoted as $W_{E \sigma \Delta \epsilon} ;^{26}$

(ii) Plastic dissipated energy per cycle denoted as $W^{27-30}$;

(iii) $W_{\sigma_{\max }}$ criterion, ${ }^{31}$ with a fatigue parameter combining plastic dissipated energy and a term based on maximal stress $\sigma_{\max }$;

(iv) $W_{\Delta \sigma}$ criterion $^{32}$ with a fatigue parameter combining plastic dissipated energy and a term based on the stress amplitude $\Delta \sigma$

(v) $W_{\sigma_{H}}$ criterion $^{33-35}$ with a fatigue parameter combining plastic dissipated energy and a term based on the maximal hydrostatic stress max $\sigma_{H}$;

(vi) $W_{\sigma_{\text {eff }}}$ criterion $^{36}$ with a fatigue parameter combining plastic dissipated energy and a term based on an effective stress $\sigma_{\text {eff }}$ which is explained in this section, in Eq. 8.

The actual short notation for the criteria emphasizes that the main ingredient is the dissipated energy per cycle denoted by $W$. The index denotes the additional terms in the expression of the fatigue parameter which are introduced in order to take into account: hydrostatic pressure, mean stress effects, etc. In this part, only LCF isothermal tests will be analysed in the case of LFC and DC A319 alloys in order to compare the influence of the casting process. TMF tests results have already been analysed in Ref. [37]. Comparaisons between A319 and A356 are under progress.
Smith-Topper-Watson, $W_{E \sigma \Delta \epsilon}$

The Smith-Topper-Watson fatigue parameter, denoted here as $W_{E \sigma \Delta \epsilon}$ is defined as

$\phi_{W_{E \sigma \Delta \epsilon}}=\sqrt{\sigma_{\max } \Delta \epsilon_{m} E}$,

where $\sigma_{\max }$ and $\Delta \epsilon_{m}$ denote the maximum stress over the cycle and the mechanical strain amplitude. It can be observed that the fatigue parameter $\phi_{W_{E \sigma \Delta \epsilon}}$ is actually a rough approximation of the dissipated energy of an uniaxial shakedown loop resized using the Young modulus. The difficulty when applying this criterion for non-isothermal loading cycles is to determine which elasticity modulus $E$ should be used in the computation. ${ }^{38}$ For the studied aluminum alloy, a variation of $200^{\circ} \mathrm{C}$ in temperatures implied a variation of approximatively $15 \%$ of the Young's modulus (see Fig. 6). The computed fatigue lifetime

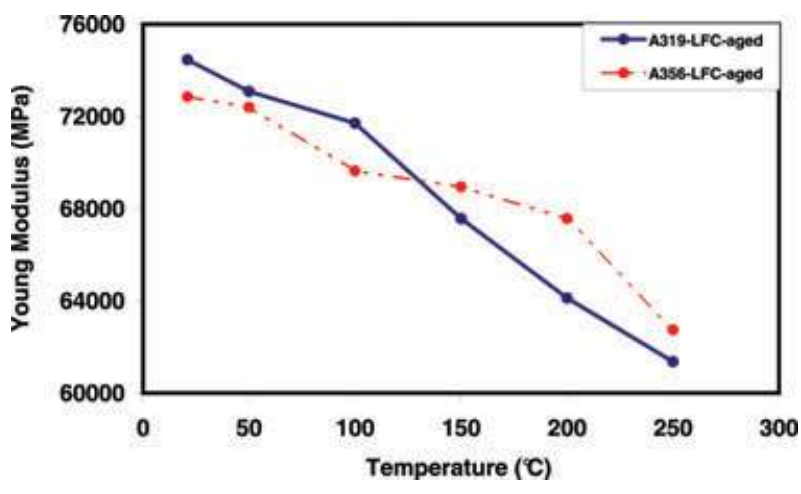

Fig. 6 Evolution of the Young Modulus $E$ as a function of temperature for the aged A319 and A356 alloys. 

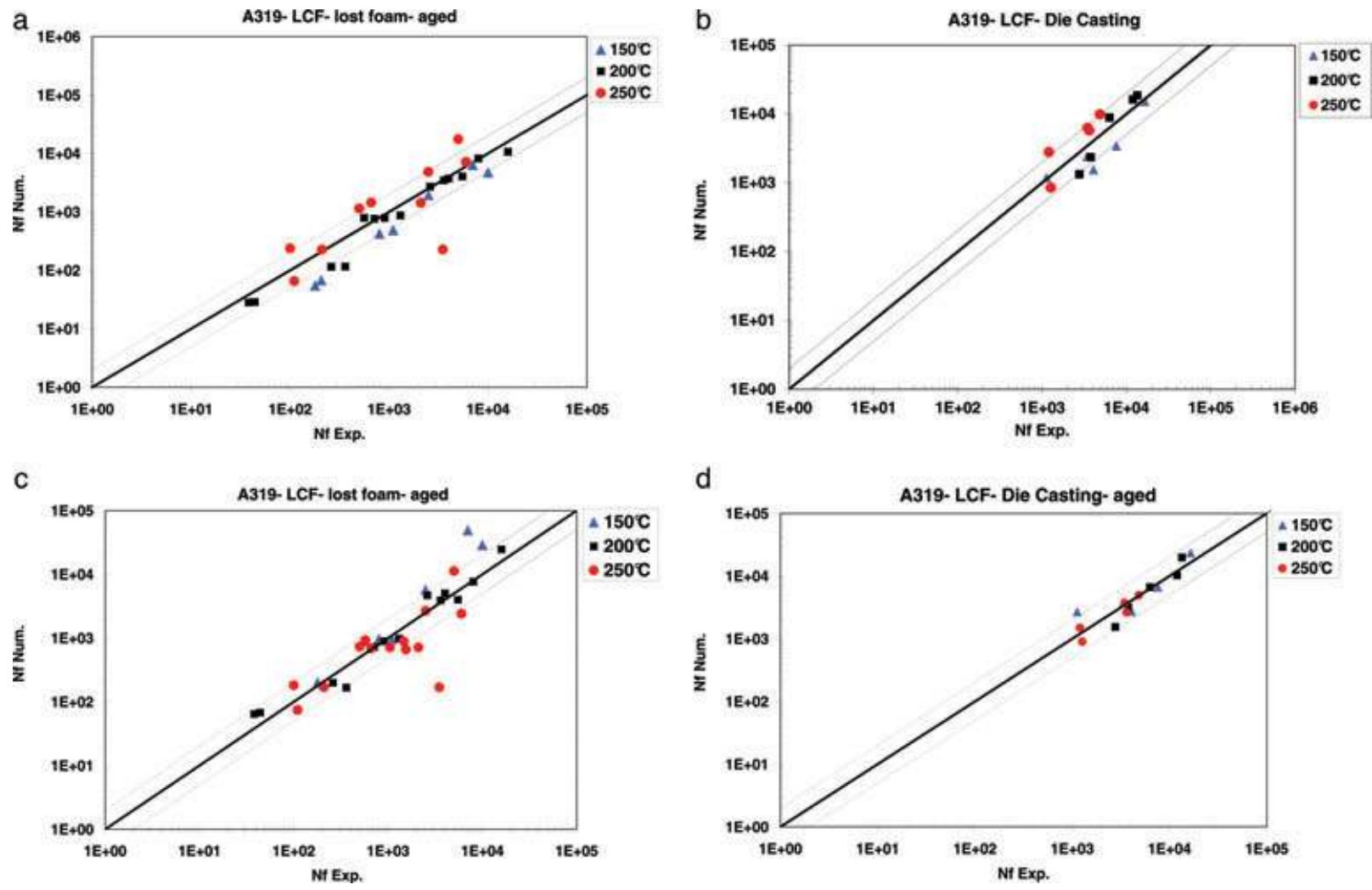

Fig. 7 Experimental fatigue life versus predicted fatigue life: (a) $W_{E \sigma \Delta \epsilon}$ criterion for A319-LFC, (b) $W_{E \sigma \Delta \epsilon}$ criterion for A319-DC, (c) $W$ criterion for A319-LFC, (d) $W$ criterion for A319-DC.

compared with experimental lifetime for the SmithTopper-Watson criterion, $W_{E \sigma \Delta \epsilon}$, is plotted in Fig. 7a and $\mathrm{b}$. As only isothermal LCF tests are analysed, each fatigue result has been analysed using the Young modulus at the test temperature. Results are presented in Fig. 7.

\section{Dissipated energy criterion, $W$}

The next criterion is characterized by the plastic dissipated energy per cycle denoted as $W$. The fatigue parameter is defined as

$\phi_{W}=\int_{\text {cycle }} \sigma: \dot{\epsilon_{p}} d t$

Let us simply recall that this criterion has been successfully used in a series of fatigue analyses on both specimens ${ }^{27-29}$ and structures. ${ }^{39}$ The advantage of this criterion is the direct relation of the fatigue properties with the plastic shakedown strain-stress loop and the exclusion of temperature varying coefficients. The results are presented on Fig. 7c and d.

\section{$W_{\sigma_{\max }}$ and $W_{\Delta \sigma}$ criteria}

Another proposal was to add an elastic strain energy associated with the tensile stress, which will directly measure a mean crack opening effect on the micro defects of the structure.

The fatigue parameter denoted here as $W_{\sigma_{\max }}$ was discussed for example in Ref. [31] and is defined as follows

$\phi_{W_{\sigma_{\max }}}=\int_{\text {cycle }} \sigma: \dot{\epsilon_{p}} d t+\frac{\left(\sigma_{\max }\right)^{2}}{2 E}$.

The modification proposed in Ref. [32], was a fatigue criterion partitioned between the plastic dissipated energy and an elastic energy over the cycle, which will be denoted as $W_{\Delta \sigma}$ in the sequel. The expression of the corresponding fatigue parameter is

$\phi_{W_{\Delta \sigma}}=\int_{\text {cycle }} \sigma: \dot{\epsilon_{p}} d t+\frac{(\Delta \sigma)^{2}}{E}$.

The results obtained with these both criteria are plotted on Fig. 8.

\section{$W_{\sigma_{H}}$ criterion}

The definition of a fatigue parameter depending only on the dissipated energy assumes that this quantity is the only driving force of the LCF damage. However, as previously underlined, the effect of mean stress in fatigue is a well 

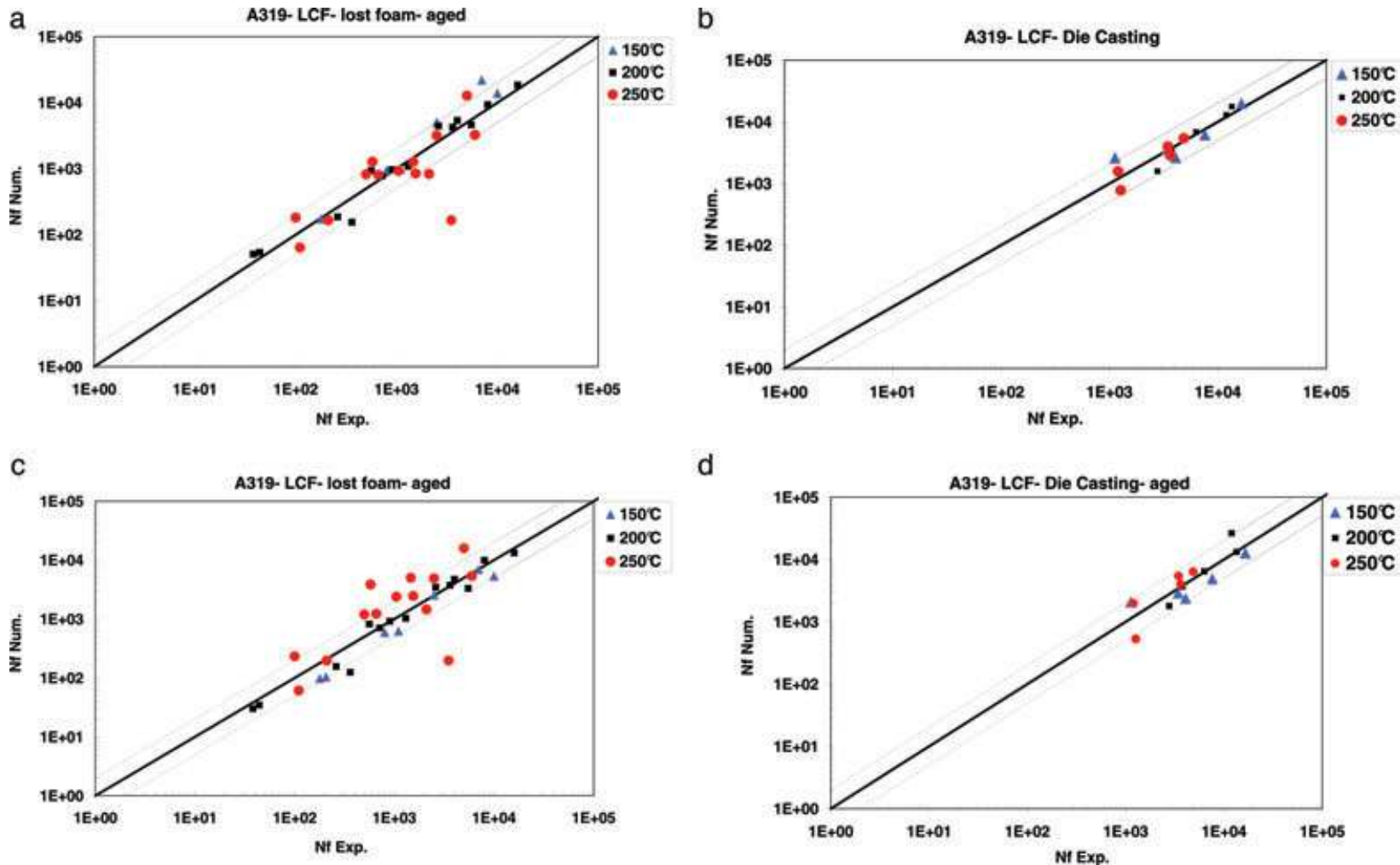

d

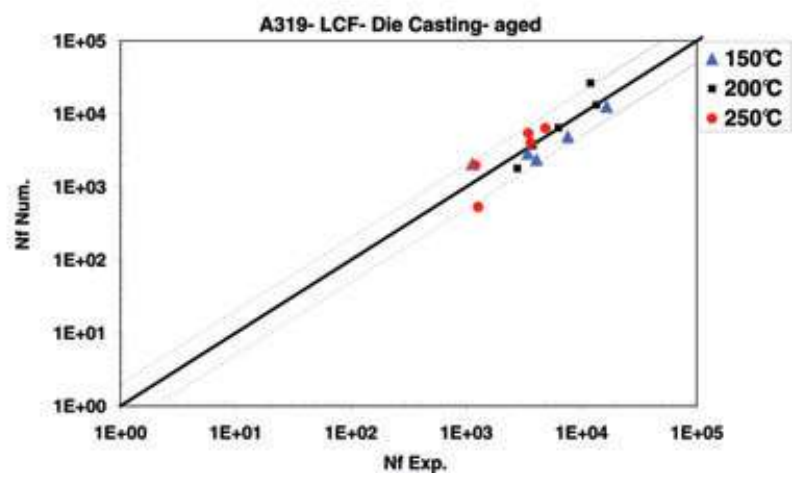

Fig. 8 Experimental fatigue life versus predicted fatigue life: (a) $W_{\sigma_{\max }}$ criterion for A319-LFC, (b) $W_{\sigma_{\max }}$ criterion for A319-DC, (c) $W_{\Delta \sigma}$ criterion for A319-LFC, (d) $W_{\Delta \sigma}$ criterion for A319-DC.

known phenomenon and the question is to define the intrinsic mechanical variable representing the effect of mean stress under an arbitrary multiaxial cyclic loading. The modification proposed in Refs. [33-35] consists in the addition of a maximal hydrostatic stress term. The corresponding fatigue criterion is denoted as $W_{\sigma_{H}}$ and its complete expression is

$\phi_{W_{\sigma_{H}}}=\int_{\text {cycle }} \sigma: \dot{\epsilon_{p}} d t+\alpha \sigma_{H}^{\max } \quad \sigma_{H}^{\max }=\max _{\text {cycle }} \frac{1}{3} \operatorname{tr}(\sigma)$,

where $\alpha$ is an additional material parameter and $\sigma_{H}^{\max }$ is the maximal hydrostatic pressure attended during the stabilized cycle. The presence of a material parameters inside the fatigue variable increases the complexity of the identification of the fatigue parameters from a linear to a nonlinear regression problem. However, it can easily be solved using existing solvers (e.g. Matlab). The comparison of experimental and estimated fatigue lifetime using this criterion is presented in Figs. 9a and $b$.

\section{$W_{\sigma_{e f f}}$ criterion}

It has been shown that the observed TMF lifetime behaviour of LFC alloys is dominated by the early initiation of cracks at the brittle phases in the eutectics, which will propagate along these phases until macroscopic failure occurs. ${ }^{22}$ Starting from these remarks and the expression of the cyclic 7 -integral for the growth of microcracks, a fatigue parameter was proposed by Dowling. ${ }^{29}$ The $\phi_{W_{\sigma_{\text {eff }}}}$ fatigue parameter considered here is based on the modified expression introduced by Heitmann et al. ${ }^{36}$ which is equally composed as a sum of elastic and plastic energy defined as

$\phi_{W_{\sigma_{\text {eff }}}}=d \int_{\text {cycle }} \sigma: \epsilon_{p} d t+c \frac{\left(\Delta \sigma_{\text {eff }}\right)^{2}}{2 E}$.

The plastic energy has been computed from the strain-stress loop as in the different previous criteria considered here and the effective stress amplitude is defined as in $^{36}$ by

$\Delta \sigma_{\text {eff }}=\Delta \sigma \cdot e \cdot(3-R)^{f} \quad R=\frac{\sigma_{\min }}{\sigma_{\max }}$,

where $E$ is the elastic modulus. $c, d, e$ and $f$ are material coefficients. Comparison of computed versus measured fatigue lifetimes using the $W_{\sigma_{\text {eff }}}$ are plotted in Fig. $9 \mathrm{c}$ and d.

\section{Regression, error analysis and discussion}

When plotting the estimated versus the measured fatigue lifetime using the dissipated energy as a fatigue parameter 

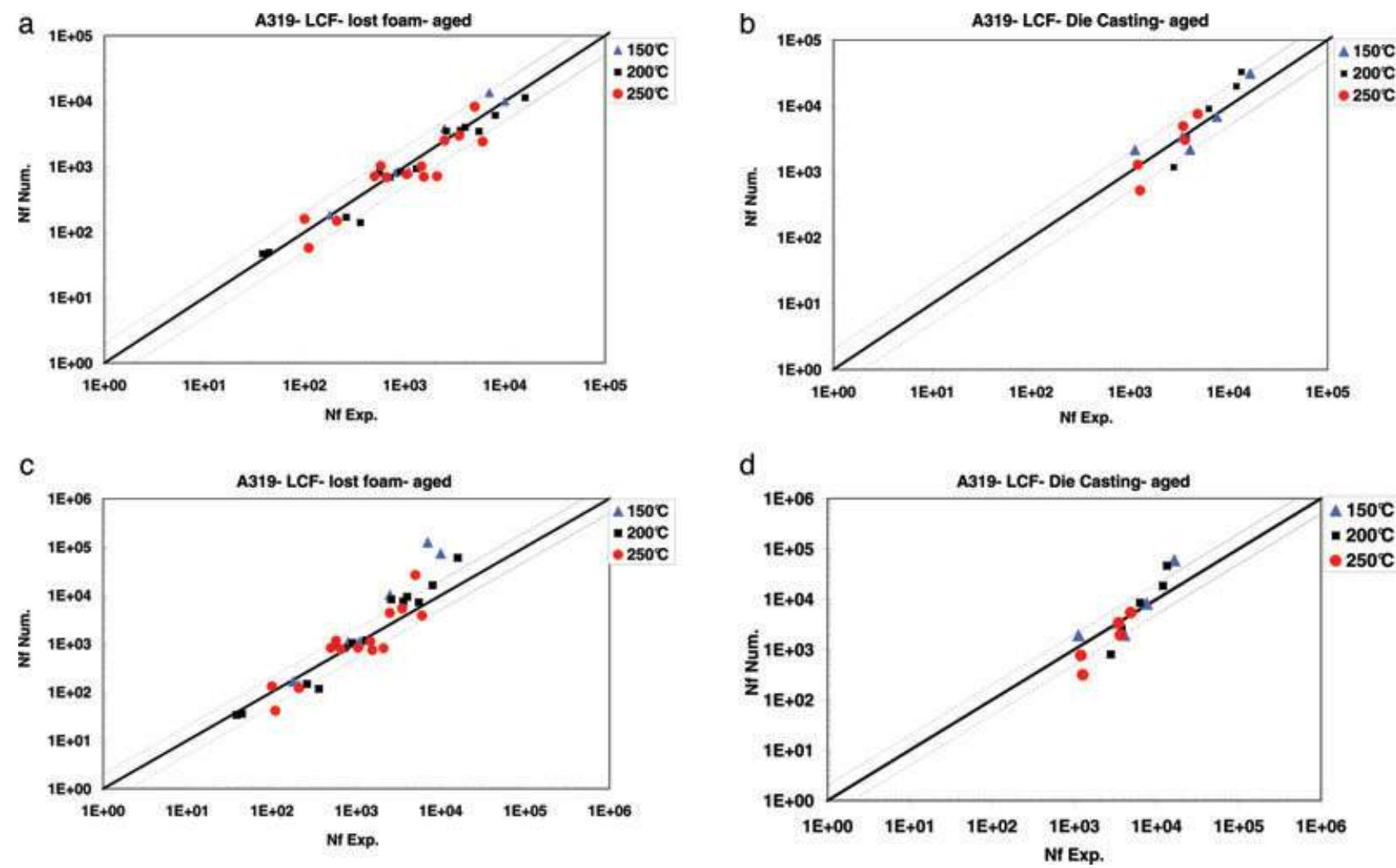

Fig. 9 Experimental fatigue life versus predicted fatigue life: (a) $W_{\sigma_{H}}$ criterion for A319-LFC, (b) $W_{\sigma_{H}}$ criterion for A319-DC, (c) $W_{\sigma_{\mathrm{eff}}}$ criterion for A319-LFC, (d) $W_{\sigma_{\text {eff }}}$ criterion for A319-DC.

(see Fig. 7c and d) one can easily identify a difference between both materials. On the one hand, a good match for the DC material can be observed, consistent with previous observations ${ }^{40}$, and on the other hand a large scattering for the LFC alloy, which implies that damage mechanisms are probably not the same and require different mechanical variables. The results obtained with $W_{E \sigma \Delta \epsilon}$ reinforce the conclusions obtained previously on cast-iron. ${ }^{38}$ An important effect of the temperature dependent Young modulus is observed on the different LCF tests. The Smith-Watson-Topper proposal seems not to be appropriate for LCF tests conducted at different temperatures. If we compare the results obtained with $W_{\sigma_{\text {eff }}}$ and $W_{\sigma_{H}}$ (see Fig. 9), a good overall match of both criteria for both materials is obtained. For $W_{\sigma_{H}}$ criterion, beside the two already defined parameters (A, B), there is just one parameter to identify $(\alpha)$, whether for $W_{\sigma_{\text {eff }}}$ criterion four parameters $(c, d, e, f)$ have to be defined in addition. $W_{\sigma_{\text {eff }}}$ criterion also presents the drawback of the temperature varying Young modulus.

In order to compare accurately the prediction capabilities of the different criteria, we propose to use the correlation coefficient $R^{2}$, corresponding to the linear association between experimental fatigue lifetimes and computed fatigue lifetimes. The $R^{2}$ is defined as in standard statistical textbooks as:

$R^{2}=\frac{\sum_{i=1}\left(N_{i}^{e x p}-\bar{N}\right)\left(\phi_{i}^{e x p}-\bar{\phi}\right)}{\sum_{i=1}\left(N_{i}^{\text {comp }}-\bar{N}\right)^{2} \sum_{i=1}\left(\phi_{i}^{\text {comp }}-\bar{\phi}\right)^{2}}$,

where $N_{i}$ and $\phi_{i}$ are the lifetimes and fatigue parameters of the experiment $i$ and the subscripts exp and comp indicate the experimental and the computed values of $\Phi$, respectively. The computed correlation coefficients for each criterion are given in Table 5. For LFC material the highest score is given by the $W_{\sigma_{H}}$ criterion, 0.923 , closely followed at 0.920 by the $W_{\sigma_{\max }}$ criterion. This means that

Table 5 Comparison between estimated results and experimental results by means of $R^{2}$

\begin{tabular}{lll}
\hline Criterion & $R^{2}(\mathrm{LFC})$ & $R^{2}(\mathrm{DC})$ \\
\hline$W_{E \sigma \Delta \epsilon}$ & 0.84 & 0.67 \\
$W$ & 0.87 & 0.83 \\
$W_{\sigma_{\max }}$ & 0.920 & 0.84 \\
$W_{\Delta \sigma}$ & 0.86 & 0.76 \\
$W_{\sigma_{H}}$ & 0.923 & 0.83 \\
$W_{\sigma_{\text {eff }}}$ & 0.89 & 0.84 \\
\hline
\end{tabular}


the expressions of both criteria capture the macroscopic effect of the microstructure on the fatigue life. When compared to other representations of the mean stress, one can state that the main interest of the $W_{\sigma_{H}}$ criterion consists in its multiaxial formulation. Therefore this damage variable is easy to implement as a post-processing to $\mathrm{FE}$ structural computations as it is intrinsic and not based on some operator dependent interpretation of the loading path. Moreover, the obtained results are consistent with recent results obtained on TMF non-isothermal tests, as shown previously by the authors. ${ }^{37}$

\section{CONCLUSION}

The purpose of this paper was to study the cyclic mechanical properties and the fatigue lifetime of A356 and A319 alloys used in cylinder heads manufactured by a LFC process. Since a few years, this process has been extensively used in the automotive industry and the induced fatigue properties are crucial in order to improve the durability and reliability of components. LCF-TMF test results revealed different cyclic mechanical and fatigue properties depending on the alloy and on the manufacturing process. Among others, one can note a higher yield stress for the A319 alloy compared with A356 and shorter lifetimes for LFC process compared with DC process for equivalent loading conditions.

In the case of A319 alloy obtained by LFC and DC processes, different thermo-mechanical energy-based fatigue criteria were used to estimate the fatigue lifetimes in isothermal LCF at different temperatures. It was shown that $W_{\sigma_{H}}$ and $W_{\sigma_{\max }}$ criteria present a good agreement between experimental and computed results. Incorporating maximum stress or hydrostatic pressure in an energetic approach seems to be a consistent proposal in order to take into account macroscopically the microstructural damage mechanisms in such aluminum alloys. Moreover, the principal interest of the $W_{\sigma_{H}}$ criterion consists in its multiaxial formulation which is consistent with a post-analysis of FE structural computations under arbitrary loadings. This conclusion is consistent with recent results obtained on TMF non-isothermal tests, as shown previously by the authors $^{37}$

\section{Acknowledgements}

The authors would like to thank David Balloy, Jean-Yves Dauphin and Jean-Charles Tissier at the Ecole Centrale de Lille, France, for their help in SEM analysis and fruitful discussion during this work. We wish to acknowledge Alexandra Marie-Louise at PSA Peugeot-Citroen for providing a vast experimental database.
This work was supported by PSA Peugeot-Citroen and has received the financial support of the French Minister of Science, which are both gratefully acknowledged.

\section{REFERENCES}

1 Sehitoglu, H. (1996) Thermal and thermomechanical fatigue of structural alloys. ASM Handbook 19, 527-556.

2 Remy, L. (2003) Thermal-mechanical fatigue (including thermal shock). In: Comprehensive Structural Integrity (Edited by I. Milne, R.O. Ritchie and B. Karihaloo), Elsevier, Vol. 5, pp. 113-200. http://dx.doi.org/10.1016/B0-08-043749-4/ 05021-7

3 Charkaluk, E. and Rémy, L. (2010) Thermal fatigue. In: Fatigue of Materials and Structures: Application to Damage and Design, Vol. 2. London: Wiley ISTE. ISBN-978-1-84821-267-1.

4 Chaboche, J. L. and Stoltz, C. (1974) Détermination des durées de vie des aubes de turbines à gaz. Revue Française de Mécanique 52, 37-47.

5 Chaboche, J. L. and Gallerneau, F. (2001) An overview of the damage approach to durability modeling at elevated temperature. Fatigue Fract. Eng. Mater. Struct. 24, 405417.

6 Nagayoshi, T. and Kodaira, T. (1993) Analysis of thermal fatigue cracks in cylinder heads. FSAE Rev. 14, 56-60.

7 Sehitoglu, H., Foglesong, T. and Maier, H. J. (2005) Precipitate effects on the mechanical behavior of aluminum copper alloys part i: Experiments. Metal. Mater. Trans. 36A, 749-761.

8 Smith, T., Maier, H., Sehitoglu, H., Fleury, E. and Allison, J. (1999) Modelling high-temperature stress-strain behavior of cast aluminum alloys. Metal. Mater. Trans. 30A, 133-146.

9 Thomas, J. J., Verger, L., Bignonnet, A. and Charkaluk, E. (2004) Thermomechanical design in the automotive industry. Fatigue Fract. Eng. Mater. Struct. 27, 887-895.

10 Fischersworring-Bunk, A., Thalmair, S., Eibl, M., Kunst, M. and Dietsche, A. (2007) High temperature fatigue and creep automotive power train application perpectives. $7 M S T$ 23, $1389-1395$

11 Lemaitre, J. and Plumtree, A. (1979) Application of damage concepts to predict creep-fatigue failures. F. Eng. Mater. Tech. 101, 284-292.

12 Sermage, J. P., Lemaitre, J. and Desmorat, R. (2000) Multiaxial creep-fatigue under anisothermal conditions. Fatigue Fract. Eng. Mater. Struct 23, 241-252.

13 Fissolo, A., Gourdin, C., Ancelet, O., Amiable, S., Demassieux, A., Chapuliot, S., Haddar, N., Mermaz, F., Stelmaszyk, J. M., Constantinescu, A., Vincent, L. and Maillot, V. (2009) Crack initiation under thermal fatigue: an overview of cea experience: Part ii (of ii): application of various criteria to biaxial thermal fatigue tests and a first proposal to improve the estimation of the thermal fatigue damage. Int. 7 . Fatigue 31, 1196-1210.

14 Gruzleski, J. E. and Closset, B. M. (1990). The Treatment of Liquid Aluminum-Silicon Alloys. American Foundrymen's Society Inc., Des Plaines, Illinois, pp. 1-18.

15 Monroe, R. W. (1992) Expendable Pattern Casting. American Foundrymen's Society Inc., Des Plaines, Illinois, pp. 1-10.

16 Heine, H. J. (1986) Evaporation pattern casting developments. Foundry M\&T, p. 36, October. 
17 Shivkumar, S., Wang, L. and Apelian, D. (1990) The lost-foam casting of aluminium alloy components. FOM 42(2), 38-42.

18 Rob Albonetti. (2000) Porosity and intermetallic formation in lost foam casting of A356 alloy. Master's thesis, The University of Western Ontario, February 2000.

19 Davis, J. R. (1993) ASM specialty handbook: aluminium and aluminium alloys. ASM Int. 719, 98-100.

20 Ammar, H. R., Samuel, A. M. and Samuel, F. H. (2008) Porosity and the fatigue behavior of hypoeutectic and hypereutectic aluminum-silicon casting alloys. Int. F. Fat. 30, 1024-1035.

21 Ran, G., Zhou, J. E. and Wang, Q. G. (2008) Precipitates and tensile fracture mechanism in a sand cast A356 aluminum alloy. 7. Mater. Proc. Tech. 207, 46-52.

22 Tabibian, S., Charkaluk, E., Constantinescu, A., Oudin, A. and Szmytka, F. (2010) Behavior, damage and fatigue life assessment of lost foam casting aluminum alloys under thermo-mechanical conditions. Proc. Eng. 2, 1145-1154.

23 Backerud, L., Chai, G. and Tamminen, J. (1990) Solidification characteristics of aluminum alloys. In Foundry alloys. Stockholm, Sweden: AFS/SkanAluminum.

24 Guillot, I., Barlas, B., Cailletaud, G., Clavel, M. and Massinon, D. (2002) Thermomechanical fatigue and aging of cast aluminium alloy: a link between numerical modelling and microstructural approach. Eur. Struct. Integr. Soc. 29, 75-84.

25 Eric Nicouleau-Bourles. (1999) Etude expérimentale et numérique du vieillissement d'un alliage d'aluminium. Application aux culasses automobiles (In French). $\mathrm{PhD}$ thesis, Ecole Nationale Supérieure des Mines de Paris.

26 Smith, K. N., Watson, P. and Topper, T. H. (1970) A stress-strain function for the fatigue of metals. $7 O M, 5$, 767-778.

27 Feltner, C. E. and Morrow, J. D. (1961) Micro-plastic strain hysteresis energy a criterion for fatigue fracture. 7. Basic Eng. Trans. A.S.M.E, 83, 15-22.

28 Morrow, J. (1965) Cyclic plastic strain energy and fatigue of metals. Int. Frict. Damp. Cyclic Plasticity STP 378, 45-87.

29 Dowling, N. E. (1972) Fatigue failure predictions for complicated stress-strain histories. FOM 7, 71-87.
30 Charkaluk, E., Bignonnet, A. and Thomas, J.-J. (2004) Dimensionnement à la fatigue thermomécanique de structures dans l'industrie automobile. Mécanique et Industries $\mathbf{5}$, 27-40.

31 Koh, S. K. (2002) Fatigue damage evaluation of a high pressure tube steel using cyclic strain energy density. Int. $\mathcal{F}$. Pressure Vessels Piping 79, 791-798.

32 Maurel, V., Remy, L., Dahmen, F. and Haddar, N. (2009) An engineering model for low cycle fatigue life based on a partition of energy and micro-crack growth. Int. F. Fatigue 31, 952-961.

33 Amiable, S., Chapuliot, S., Constantinescu, A. and Fissolo, A. (2005) A comparison of lifetime prediction methods for a thermal fatigue experiment. Int. F. Fatigue 28, 692-706.

34 Amiable, S., Chapuliot, S., Constantinescu, A. and Fissolo, A. (2006) A computational lifetime prediction for a thermal shock experiment, Part I : thermomechanical modeling and lifetime prediction. Fatigue Fract. Eng. Mater. Struct. 29, 209-217.

35 Amiable, S., Chapuliot, S., Constantinescu, A. and Fissolo, A. (2006) A computational lifetime prediction for a thermal shock experiment, Part II : discussion on different fatigue criteria. Fatigue Fract. Eng. Mater. Struct. 29, 219 227.

36 Heitmann, H. H., Vehoff, H. and Neumann, P. (1984) Life Prediction for Random Load Fatigue based on the Growth Behaviour of Microcracks. 6th Int. Conf. Fracture, New Delhi, edited by S.R. Valluri et al., Pergamon Press Ltd, Oxford, vol. 4, pp. 3599-3606.

37 Tabibian, S., Charkaluk, E., Constantinescu, A., Szmytka, F. and Oudin, A. (2012) TMF-LCF life assessment of a Lost Foam Casting A319 aluminum alloy. Int. F. Fatigue, in press.

38 Charkaluk, E. and Constantinescu, A. (2000) An energetic approach in thermomechanical fatigue for silicon molybdenum cast iron. Mater. High Temperatures 3, 373-380.

39 Constantinescu, A., Charkaluk, E., Lederer, G. and Verger, L. (2004) A computational approach to thermomechanical fatigue. Int. F. Fatigue 26, 805-818.

40 Verger, L. (2002) Sur la fatigue thermomécanique d'un alliage d'aluminium (In French). PhD thesis, Ecole polytechnique. 